\title{
Pulmonary artery pressure and the acute chest syndrome in homozygous sickle cell disease
}

\author{
Charles E Denbow, Edward E Chung, Graham R Serjeant
}

\begin{abstract}
Objective-To investigate whether attacks of acute chest syndrome affected pulmonary artery pressure in patients homozygous for sickle cell disease.

Main outcome measures-Pulmonary artery pressure, assessed by non-invasive echocardiographic techniques.

Patients-20 patients with homozygous sickle cell disease with a history of at least six episodes of acute chest syndrome and in 20 age, sex, and height matched controls with homozygous sickle cell disease without a history of acute chest syndrome.

Results-There was no difference in any of the echocardiographic or Doppler indices between these two groups.

Conclusions-Repeated attacks of acute chest syndrome by the mean age of 12 (range eight to 16) years have not had a discernible effect upon pulmonary artery pressure.
\end{abstract}

(Br Heart f 1993;69:536-538)

Pulmonary fibrosis, and consequently pulmonary hypertension, are believed to compromise right ventricular function resulting in cor pulmonale in some patients with homozygous sickle cell disease. The acute chest syndrome representing a complex pathology of infection, infarction, and pulmonary sequestration is a common cause of morbidity and mortality in homozygous sickle cell disease. The Jamaican cohort study in which children with this disease have been followed up prospectively from birth provides an opportunity to assess the effect of repeated episodes of the acute chest syndrome on pulmonary artery pressure. We report pulmonary haemodynamic findings in 20 age and sex matched pairs with homozygous sickle cell disease with and without a history of multiple episodes of the acute chest syndrome.

\section{Patients and methods}

The patients attended the sickle cell clinic of the University Hospital of the West Indies, Kingston, Jamaica, and participated in a cohort study of sickle cell disease. The cohort study was based on all cases of sickle cell disease detected during the screening of 100000 consecutive normal deliveries at the main Government maternity hospital (Victoria Jubilee Hospital) between June 1973 and
December 1981.' The study includes $315^{\circ}$ children with SS disease of whom 34 have $\overline{\bar{c}}$

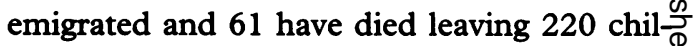
dren aged 10-18.5 years under observation. 20 All children have been followed up prospec-s tively from birth on a schedule of assessments $\overrightarrow{0}$ every three months disrupted by occasionaldefaults. As these children all attend the sick- $\bar{\omega}$ le cell clinic as their primary clinic all major? events and complications have been recordeo from birth.

The acute chest syndrome was defined as aic combination of cough, shortage of breath, pleuritic symptoms, and fever in associationwith clinical signs of parenchymal disease with or without radiological evidence of pul $-\complement$ monary infiltrates. Twenty children of the cohort study had developed six or more $\vec{\theta}$ attacks of the acute chest syndrome and thesew were matched by age and sex with 20 SS children without any history of acute chest syndrome. All 40 patients, aged 11-18 years, were studied by echocardiography while clini-卷 cally well during a three week period in $\bar{Q}$ January and February 1992. This was carried out by two cardiologists (EEC, CED) with-을 out knowledge of the pulmonary state.

ECHOCARDIOGRAPHIC MEASUREMENTS

Cross sectional echocardiography with Doppler studies were performed with an:Advanced Technology Laboratories Ultramark 4 Echocardiograph. The patients were examined in the supine and left lateral positions with the transducer along the third too fifth left intercostal space in the parasternal ${ }_{\supset}$ position. Recordings and measurements were made according to the criteria of the American Society of Echocardiography. ${ }^{3}$

The left ventricular dimension was mea- $N$ sured from a point just below the mitral $\omega$ leaflets at the level of the chordae tendineae The left ventricular end diastolic dimensiono (Dd) was measured at the onset of the QRS complex of the electrocardiogram, and the left ventricular end systolic dimension (Ds) at ${ }_{0}^{0}$ the point of maximal posterior movement of the ventricular septum. Left ventricular end $\stackrel{?}{\stackrel{P}{D}}$ diastolic volume (LVEDV) and left ventricu- $\frac{\circ}{\sigma}$ lar ejection fraction (LVEF) were estimated by the methods of Meyer et al. ${ }^{4}$ Left ventricu- $\delta$ lar end diastolic volume was estimated from? the regression equation:

LVEDV $=-19 \cdot 1+14 \cdot 6 \mathrm{Dd}+0.02 \mathrm{Dd}^{3}$.

Left ventricular ejection fraction was estimated from the formula:

$$
\mathrm{LVEF}=1-(\mathrm{As} / \mathrm{Ad}) \times\left(\mathrm{Ds} / \mathrm{Dd}^{2}\right)
$$


where As/Ad was the ratio of left ventricular end systolic and end diastolic major axis dimensions and was assumed to be 0.9 , corresponding to a $10 \%$ shortening of this axis.

The stroke volume was derived from the product of left ventricular end diastolic volume and ejection fraction. Cardiac output was calculated from the stroke volume and heart rate.

\section{PULSED DOPPLER TECHNIQUE}

Pulmonary artery velocities were recorded with the sample volume just beyond the pulmonary valve in the parasternal short axis view according to the method of Kitabatake et al. ${ }^{5}$ The acceleration time (ACT) was measured as the time to peak velocity. Mean pulmonary artery pressure (mean PAP) was estimated by the formula:

$$
\text { mean PAP }=79-0.45 \text { ACT corr }
$$

where ACT corr $=\mathrm{ACT}(\mathrm{ms}) \div \mathrm{R} \mathrm{R}$ interval.

Tricuspid regurgitation velocity, where recordable, was measured in the parasternal short axis or four chamber view. Pulmonary artery systolic pressure (PAs) was assumed to be equal to right ventricular systolic pressure in the absence of pulmonary stenosis. Right ventricular systolic pressure was calculated by adding $14 \mathrm{~mm}$ to the right ventricular to right atrial pressure gradient deduced from the modified Bernoulli equation, pressure gradient $(\mathrm{mm} \mathrm{Hg})=4$ velocity $^{2}$.

Pulmonary regurgitant velocity when present was recorded in the parasternal short axis view. The pulmonary artery to right ventricular pressure gradient was calculated from the modified Bernoulli equation and the pulmonary artery diastolic pressure (PAd) calculated by adding $8 \mathrm{~mm}$ to this gradient.

Pulmonary vascular resistance was calculated by dividing the pulmonary artery pressure by the cardiac index.

\section{Results}

The table summarises the pertinent cardiovascular findings in the patients with and without repeated attacks of acute chest syn-

Cardiovascular findings in 20 patients with and 20 without repeated episodes of acute chest syndrome

\begin{tabular}{|c|c|c|c|}
\hline & $\begin{array}{l}\text { Acute chest } \\
\text { syndrome } \\
\text { Median (range) }\end{array}$ & $\begin{array}{l}\text { No acute chest } \\
\text { syndrome } \\
\text { Median (range) }\end{array}$ & $p$ Value ${ }^{\star}$ \\
\hline $\begin{array}{l}\text { Heart rate/min } \\
\text { Stroke volume }(\mathrm{ml}) \\
\text { Cardiac output }(1 / \mathrm{min}) \\
\text { Body surface area }\left(\mathrm{m}^{2}\right) \\
\text { Cardiac index }\left(1 / \mathrm{min} / \mathrm{m}^{2}\right) \\
\text { LVEDV }(\mathrm{ml}) \\
\text { LVEF } \\
\text { Mean PAP (mm Hg) } \\
\text { PAs (mm Hg) } \\
\text { PAd (mm Hg) } \\
\text { PVR (dyn s } \\
\text { ACT (ms) } \\
\text { RVET (ms) } \\
\text { ACT/RVET }\end{array}$ & $\begin{array}{c}102(79-130) \\
80 \cdot 0(39-177) \\
8 \cdot 25(4 \cdot 4-16 \cdot 1) \\
1 \cdot 22(0 \cdot 89-1 \cdot 53) \\
7 \cdot 44(3 \cdot 87-14 \cdot 60) \\
135(66-285) \\
0 \cdot 62(0 \cdot 53-0 \cdot 75) \\
19 \cdot 5(7-43) \\
30(20-39) \ddagger \\
9(8-10) 9 \\
148(54-419) \\
110(60-120) \\
260(220-300) \\
0 \cdot 40(0 \cdot 23-0 \cdot 46)\end{array}$ & $\begin{array}{c}97(67-125) \\
77 \cdot 5(48-128) \\
7 \cdot 35(4 \cdot 9-16 \cdot 0) \\
1 \cdot 28(0 \cdot 91-1 \cdot 71) \\
6 \cdot 20(3 \cdot 47-12 \cdot 49) \\
131(84-237) \\
0 \cdot 59(0 \cdot 43-0 \cdot 74) \\
19 \cdot 5(7-30) \\
27(17-34) \oint \\
9(8-14) \| \\
205(35-386) \\
100(80-120) \\
260(200-320) \\
0 \cdot 41(0 \cdot 32-0 \cdot 48)\end{array}$ & $\begin{array}{l}0 \cdot 24 \\
0 \cdot 70 \\
0 \cdot 33 \\
0 \cdot 14 \\
0 \cdot 25 \\
0 \cdot 81 \\
0 \cdot 16 \\
0 \cdot 63 \\
0 \cdot 36 \dagger \\
0 \cdot 66 \dagger \\
0 \cdot 31 \\
0 \cdot 73 \\
0 \cdot 29 \\
0 \cdot 64\end{array}$ \\
\hline
\end{tabular}

*Wilcoxon test; †Mann-Whitney $U$ test; Number of patients $=20$ except $\ddagger n=6 ; \S n=8$; $\|\mathrm{n}=7 ;\| \mathrm{n}=1$; ACT, acceleration time; PAd, pulmonary artery diastolic pressure; LVEDV, left ventricular ejection fraction; PAs, pulmonary artery systolic pressure; LVEF, left ventricular ejection fraction; PVR, pulmonary vascular resistance; Mean PAP, mean pulmonary artery pressure; RVET, right ventricular ejection time. drome. No significant differences between the groups were found. Tricuspid regurgitation allowed the calculation of pulmonary artery systolic pressure in $6 / 20$ with a history of the acute chest syndrome and in $8 / 20$ controls. Pulmonary regurgitation allowed the calculation of pulmonary artery diastolic pressure in $7 / 20$ with a history of the acute chest syndrome and in $11 / 20$ controls.

\section{Discussion}

Patients with sickle cell disease are more prone to attacks of acute pulmonary pathology that in the absence of a clear pathological mechanism is usually referred to as the acute chest syndrome. In the Jamaican cohort study of sickle cell disease, the incidence of the acute chest syndrome was four times greater than in normal controls by the age of four years. ${ }^{6}$ Although the acute chest syndrome is an important cause of morbidity and mortality at all ages, ${ }^{7}$ it is unclear whether patients recovering from attacks sustain permanent damage to the alveolar or pulmonary capillary system.

A recent review of experience with acute chest syndrome in the cohort study noted that 31 patients had had six episodes or more by a mean age of 12 years and controlled observations in 20 of these patients noted a significant reduction in peak expiratory flow (PEF) compared with 20 controls with homozygous sickle cell disease matched for age, sex, and height who had never had the acute chest syndrome. ${ }^{8}$ The mechanism of reduction in PEF was not clearly understood and could not be investigated further in the absence of other pulmonary function tests, but one possibility was an increased pulmonary fibrosis.

Such a diffuse pulmonary fibrosis might also be expected to reduce the distensibility of pulmonary arterioles and capillaries contributing to an increase in pulmonary artery pressure. It was therefore of interest to study pulmonary artery pressure in the same 20 matched pairs previously studied by PEF to find whether repeated attacks of acute chest syndrome had resulted in an increase in pulmonary artery pressure. We have not detected any significant differences in echocardiographic or Doppler values between the two groups.

This finding is open to several interpretations. The acute chest syndrome may resolve completely without permanent fibrotic changes. The reduction in PEF noted in these children, however, indicates some residual change and Powars et al found a strong co-relation between number of acute chest syndrome events and chronic pulmonary fibrosis (sickle cell chronic lung disease).$^{9}$ It is possible that the number of clinical events in these children is still too few to permanently compromise pulmonary vascular flow and that more years of pulmonary events are necessary to exceed the adaptive capacity of the pulmonary vascular bed. This is plausible although Powars et al reported cases of 
chronic lung disease in patients with sickle cell disease before the age of 10 years $^{9}$ and an expected trend between mean pulmonary artery pressure and number of acute chest syndrome events did not occur in the present study. Finally it could be argued that there is no relation between pulmonary fibrosis in sickle cell disease and the development of pulmonary hypertension. Although pulmonary hypertension is commonly assumed to be present in sickle cell disease, well documented cases are few. Collins and Orringer found only one case with confirmation of pulmonary hypertension by cardiac catheterisation on careful review of published information, and added two more of their own. ${ }^{10}$ On the other hand, a study with Doppler echocardiographic recording of pulmonary artery velocities found evidence of at least moderate pulmonary hypertension in $40 \%$ of adults with homozygous sickle cell disease. ${ }^{11}$

Although the present study has not used cardiac catheterisation, the validity of the non-invasive method of deriving pulmonary artery systolic pressure from the tricuspid regurgitant velocity has been well documented by simultaneous Doppler and catheterisation studies. ${ }^{12}$ Also, the mean pulmonary artery pressure calculated for heart rate correlates well with invasively determined systolic and mean pulmonary artery pressure. ${ }^{13}$ There is no reason to believe that this method is invalidated by the cardiovascular changes of sickle cell disease and prospective studies will be continued to clarify the relation between acute chest syndrome events and pulmonary artery pressure in these patients.
We thank Dr Peter Thomas for assistance with the statistical tests and the Sickle Cell Trust for donation of the ATL ultrasound system.

1 Serjeants BE, Forbes M, Williams LL, Serjeant GR. Screening cord bloods for detection of sickle cell disease in Jamaica. Clin Chem 1974;20:666-9.

2 Serjeant GR, Serjeant BE, Forbes M, Hayes RJ, Higgs 岂 $D R$, Lehmann $H$. Haemoglobin gene frequencies in the Jamaican population: a study of 100000 newborns. $B r \mathcal{F}$ Haematol 1986;64:253-62.

3 Sahn DJ, De Maria A, Kisslo J, Weyman A. Recommendations regarding quantitation in $M$ mode Recommendations regarding quantitation in $M$ mode echocardiography: results of a survey of echocardic-

4 Meyer RA, Stockert J, Kaplan S. Echographic determina- $\frac{\bar{c}}{T}$ tion of left ventricular volumes in pediatric patients. $\mathbb{D}$ Circulation 1975;51:297-303.

5 Kitabatake $A$, Inoue $M$, Asao $M$, et al. Non invasive eval- ญ uation of pulmonary hypertension by a pulsed Doppler technique. Circulation 1983;68:302-9.

6 De Ceulaer K, McMullen KW, Maude GH, Keatinge R, Serjeant GR. Pneumonia in young children with homozygous sickle cell disease: risk and clinical features. Eur $\mathcal{F}$ Pediatr 1985;144:255-8.

7 Thomas AN, Pattison C, Serjeant GR. Causes of death in sickle-cell disease in Jamaica. BMF 1982;285:633-5.

8 Bowen EF, Crowston JG, De Ceulaer K, Serjeant GR. ๑ Peak expiratory flow rate and the acute chest syndrome os in homozygous sickle cell disease. Arch Dis. Child of 1991;66:330-2.

9 Powars D, Weidman JA, Odom-Maryon T, Niland JC, O Johnson C. Sickle cell chronic lung disease: prior 0 morbidity and the risk of pulmonary failure. Medicine 1988;67:66-76.

10 Collins FS, Orringer EP. Pulmonary hypertension and cor $\subseteq$ pulmonale in the sickle hemoglobinopathies. $\mathrm{Am} f \mathrm{Med}$ 1982;73:814-21.

11 Simmons BE, Santhanam V, Castaner A, Rao KRP, $\vec{\theta}$ Sachdev N, Cooper R. Sickle cell heart disease. Two- $\mathbb{0}$ dimensional echo and Doppler ultrasonographic find- $\omega$ ings in the hearts of adult patients with sickle cell anemia. Arch Intern Med 1988;148:1526-8.

12 Currie PJ, Seward JB, Chan KL, et al. Continuous wave Doppler determination of right ventricular pressure: a simultaneous Doppler catheterisation study in 127 patients. $¥ \mathrm{Am}$ Coll Cardiol 1985;6:750-6.

13. Chan KI, Currie PJ, Seward JB, Hagler DJ, Mair DD Tajik AJ. Comparison of three Doppler ultrasound methods in the prediction of pulmonary artery pressure. methods in the prediction of pulm 